University of Nebraska - Lincoln

DigitalCommons@University of Nebraska - Lincoln

\title{
Serial Reversal Learning and the Evolution of Behavioral Flexibility in Three Species of North American Corvids (Gymnorhinus cyanocephalus, Nucifraga columbiana, Aphelocoma californica)
}

\author{
Alan B. Bond \\ University of Nebraska - Lincoln, abond1@unl.edu \\ Alan Kamil \\ University of Nebraska - Lincoln, akamil1@unl.edu \\ Russell P. Balda \\ Northern Arizona University, Russell.Balda@nau.edu
}

Follow this and additional works at: https://digitalcommons.unl.edu/bioscibehavior

Part of the Behavior and Ethology Commons

Bond, Alan B.; Kamil, Alan; and Balda, Russell P., "Serial Reversal Learning and the Evolution of Behavioral Flexibility in Three Species of North American Corvids (Gymnorhinus cyanocephalus, Nucifraga columbiana, Aphelocoma californica)" (2007). Papers in Behavior and Biological Sciences. 20. https://digitalcommons.unl.edu/bioscibehavior/20

This Article is brought to you for free and open access by the Papers in the Biological Sciences at DigitalCommons@University of Nebraska - Lincoln. It has been accepted for inclusion in Papers in Behavior and Biological Sciences by an authorized administrator of DigitalCommons@University of Nebraska - Lincoln. 
Published in Journal of Comparative Psychology 121:4 (2007), pp. 372-379; doi: 10.1037/0735-7036.121.4.372 Copyright @ 2007 American Psychological Association. Used by permission. "This article may not exactly replicate the final version published in the APA journal. It is not the copy of record." http://www.apa.org/journals/com/

This research was supported in part by National Science Foundation Grants IBN-9421807 and IBN-9982883 and National Institute of Mental Health Grant R01-MH069893. Animal maintenance and treatment conditions were approved by the University of Nebraska Institutional Animal Care and Use Committee, Project Number 01-111-067. We thank C. Wei, L. Morrison, and R. Benford for valuable comments and suggestions and C. Smith for training and testing the birds.

\title{
Serial Reversal Learning and the Evolution of Behavioral Flexibility in Three Species of North American Corvids (Gymnorhinus cyanocephalus, Nucifraga columbiana, Aphelocoma californica)
}

\author{
Alan B. Bond \& Alan C. Kamil \\ School of Biological Sciences, University of Nebraska-Lincoln \\ Russell P. Balda \\ Department of Biological Sciences, Northern Arizona University \\ Corresponding author - Alan B. Bond, School of Biological Sciences, University of Nebraska-Lincoln, \\ 348 Manter Hall, Lincoln, NE 68588-0118; email abond1@unl.edu
}

\begin{abstract}
In serial reversal learning, subjects learn to respond differentially to 2 stimuli. When the task is fully acquired, reward contingencies are reversed, requiring the subject to relearn the altered associations. This alternation of acquisition and reversal can be repeated many times, and the ability of a species to adapt to this regimen has been considered as an indication of behavioral flexibility. Serial reversal learning of 2-choice discriminations was contrasted in 3 related species of North American corvids: pinyon jays (Gymnorhinus cyanocephalus), which are highly social; Clark's nutcrackers (Nucifraga columbiana), which are relatively solitary but specialized for spatial memory; and western scrub jays (Aphelocoma californica), which are ecological generalists. Pinyon jays displayed significantly lower error rates than did nutcrackers or scrub jays after reversal of reward contingencies for both spatial and color stimuli. The effect was most apparent in the 1st session following each reversal and did not reflect species differences in the rate of initial discrimination learning. All 3 species improved their performance over successive reversals and showed significant transfer between color and spatial tasks, suggesting a generalized learning strategy. The results are consistent with an evolutionary association between behavioral flexibility and social complexity.
\end{abstract}

Keywords: behavioral flexibility, complexity, modularity, cognitive evolution, innovation

Social or physical environments that are relatively complex, in that they are less predictable or more highly structured, are thought to impose distinctive perceptual and cognitive requirements (de Waal \& Tyack, 2003; Godfrey-Smith, 2002; Tomasello \& Call, 1997), though the nature of these requirements is not well understood. One common theme in the recent literature is that complex environments should select for greater behavioral flexibility, that species living in such circumstances should respond more rapidly to environmental changes and should be more ready to seek out alternative solutions to the problems they encounter (Day, Crews, \& Wilczynski, 1999; Jones, 2005; Robinson, 1990; Tomasello \& Call, 1997). What is meant by this prediction varies from one author to another, however: There are at least three different, though presumably related, connotations of flexibility in the behavioral literature.

In one sense of the term, flexible animals modify their behavior based on brief, limited experience, responding rapidly to subtle variations in consequences or context (Easton, 2005). This is similar to the use of flexibility in economics, where it refers to the ability of a business to change or react with little penalty in time, effort, cost, or performance (Upton, 1994). Flexible animals have also been characterized as versatile, exploratory, and playful, modifying their behavior even when circumstances do not require it (Burghardt, 2005; Diamond \&
Bond, 1999; Lorenz, 1981). This is related to the use of flexibility in engineering, where flexible systems are those that can easily be modified for use in applications other than the ones for which they were specifically designed (IEEE, 1990). Several researchers have viewed this type of behavioral flexibility as a primary source of creativity and innovation (Reader \& Laland, 2003; Sol, Timmermans, \& Lefebvre, 2002).

Finally, the flexibility of behavior patterns that can be readily and repeatedly reversed corresponds to the medical connotation of flexibility, referring to the pliancy or elasticity of a joint (Holt, Holt, \& Pelham, 1996). This flexibility concept is perhaps the most congenial of the three to objective analysis, as it subsumes the cognitive abilities required by serial reversal learning (Davey, 1989; Mackintosh, 1974). Reversal learning is an operant procedure that involves training an animal on a particular discrimination task and then, when a criterion level of accuracy has been reached, abruptly reversing the reward contingencies. To continue to be rewarded, the animal must cease responding to the originally reinforced stimulus and switch to the previously unreinforced alternative. In serial reversal learning, this alternation of training to criterion and subsequent reversal of reinforcement is repeated many times in succession. The procedure does not appear to emulate directly any natural aspect of an animal's ecology or life history, 
but species that can recover more rapidly from the reversed association are undeniably more flexible, at least in this sense of the term (Day et al., 1999).

Behavioral flexibility is unlikely to be a generalized attribute. Rather, one would expect animals to show greater flexibility in those specific aspects of life in which they experience higher levels of complexity and unpredictability. Species that commonly deal with fluctuating ecological resources, for example, should exhibit greater flexibility in their investment of time and effort in foraging than those that occupy more stable and reliable niches (Davey, 1989; Day et al., 1999; Shettleworth, 1998). Species that live in spatially complex and heterogeneous environments should exhibit greater perceptual or attentional flexibility than those that live in simpler, more uniform circumstances (Jones, 2005; Robinson, 1990). And species that live in permanent social groups, in which individuals display a wide range of social behaviors and types of relationship, should face greater demands for flexibility in their responses to social stimuli than more solitary or asocial species (Blumenstein \& Armitage, 1998; Easton, 2005; Shultz \& Dunbar, 2006). Because it entails flexible responding to a fixed set of stimuli based on a fluctuating reward regimen, reversal learning appears to bear most resemblance to the demands of a complex social system. This prediction is susceptible to testing by comparing reversal performance in an appropriate set of related species.

Evolutionary accounts of comparative tests of serial reversal enjoyed a brief vogue about 40 years ago, based on the assumption that the speed with which animals improved their performance over successive reversals reflected species differences in "intelligence" or "learning ability" (Bitterman, 1965). A remarkable range of vertebrates were tested in these experiments (Davey, 1989; Mackintosh, 1974), but procedural and contextual factors, which always pose difficulties for comparisons among phylogenetically disparate organisms (Breland \& Breland, 1961), confounded the interpretation of interspecific differences (Macphail, 1982; Tomasello \& Call, 1997; Warren, 1965). A more rigorous and productive approach to testing models of cognitive evolution is the comparative method, in which sets of closely related species are chosen that differ from one another in some focal aspect of their natural history (Felsenstein, 1985; Harvey \& Pagel, 1991; Kamil, 1988). Experiments are conducted to determine whether differences in cognitive capabilities across species can be predicted from contrasts in their ecology or life history (Balda, Kamil, \& Bednekoff, 1996; Bond, Kamil, \& Balda, 2003; Day et al., 1999). The use of phylogenetically related species provides an effective control for the influence of common descent. If the cognitive capability is not an evolutionary consequence or correlate of the contrasts in natural history, the null hypothesis would predict it to be displayed to a similar degree in closely related species. When such comparisons are performed iteratively on appropriately selected sets of species, this method can provide compelling evidence for evolutionary causation as has been shown in comparative studies of spatial memory in food-caching birds (reviewed in Balda et al., 1996; Shettleworth, 1998).

North American corvids provide an attractive proving ground for investigating the evolution of behavioral flexibility, as many of these species experience diverse forms of environmental complexity. Pinyon jays (Gymnorhinus cyanocephalus) live in large, structured groups, foraging as a permanent flock and breeding colonially (Marzluff \& Balda, 1992), suggesting that they experience many social interactions, changing over time, with multiple individuals (Bond et al., 2003; Paz-y-Miño, Bond, Kamil, \& Balda, 2004). Clark's nutcrackers (Nucifraga columbiana) are comparatively asocial, but each year, individual birds bury thousands of pine seeds in unmarked locations across their territories, relocating them later by spatial memory (Bednekoff, Balda, Kamil, \& Hile, 1997; Tomback, 1998; Vander Wall \& Balda, 1981). Because nutcrackers must remember not just where seeds have been cached but also which previous caches have been depleted, their management of spatial memory might be thought to require significant cognitive flexibility (Bednekoff \& Balda, 1997; Lewis \& Kamil, 2006). Western scrub jays (Aphelocoma californica) have a broad dietary niche, making use of a variety of food extraction techniques, and they show a moderate ability to adapt their social systems to suit geographical differences in resource availability (Carmen, 2004; Curry, Peterson, \& Lange, 2002). They thus appear to be a more generalist species with respect to both ecology and social behavior and might also, therefore, be expected to show significant behavioral flexibility.

Aside from their foraging biology and social systems, however, these three jay species are relatively comparable. They are sympatric over large parts of the mountains and high deserts of the American southwest. They make use of similar food resources (Balda, 2002; Curry et al., 2002; Tomback, 1998) and even occasionally feed in neighboring pine trees (Balda \& Kamil, 1998). They are also taxonomically comparable. Aphelocoma and Gymnorhinus are among the most closely related of the six corvid genera endemic to the New World (Espinosa de los Monteros \& Cracraft, 1997). Nucifraga is an Old World genus from an earlier corvid radiation, but it is still classified in the same tribe as the New World jays (Monroe \& Sibley, 1993). If social complexity were more influential than ecological complexity in determining behavioral flexibility in these corvids, we would predict that pinyon jays would show better reversal performance than scrub jays or nutcrackers. If ecological complexity were more influential, we would expect either nutcrackers or scrub jays to show higher levels of flexibility.

We tested these hypotheses using serial reversals of a twochoice discrimination task. In earlier comparative experiments, nutcrackers have shown superior capabilities on a number of tasks involving spatial memory (Bednekoff et al., 1997; Kamil, Balda, \& Olson, 1994; Olson, Kamil, Balda, \& Nims, 1995). These differences disappeared when nonspatial tasks were used, however, suggesting a separation of memory for spatial stimuli from memory for other, intrinsic stimulus features (Olson et al., 1995). It is possible, therefore, that the flexibility demonstrated in serial reversal might also vary as a function of stimulus modality. We therefore compared the performance of the three corvid species on serial reversal of color stimuli (Experiment 1), as well as on serial reversal of spatial positions (Experiment 2). To control for the possibility of carryover effects, the spatial reversal experiment was subsequently repeated using naive pinyon jays and scrub jays (Experiment 3).

\section{General Method}

\section{Subjects}

Five individuals of each of the three species (pinyon jays, Gymnorhinus cyanocephalus; Clark's nutcrackers, Nucifraga columbiana; and western scrub jays, Aphelocoma californica) were 
captured in the field in central Colorado or northern Arizona and were subsequently maintained in individual cages in environmentally controlled rooms $\left(22^{\circ} \mathrm{C}\right.$; 14:10-hr light-dark cycle) on a diet of turkey starter, sunflower seeds, parrot pellets, meal worms, pine nuts, and a vitamin supplement. During experiments, subjects were kept at $85 \%$ to $90 \%$ of their free-feeding weights, but they had unlimited access to grit and water. Four of the nutcrackers had previously been used in open-room experiments, but all subjects were initially naive to operant procedures.

\section{Apparatus}

Experiments were conducted in operant boxes equipped with three $2.5-\mathrm{cm}$ diameter pecking keys spaced at $7.6-\mathrm{cm}$ intervals across the front wall of the chamber, $22.5 \mathrm{~cm}$ above the floor. A perch was placed in front of the key array and adjusted so that the centers of the keys were approximately at eye level for each species. During trials, the keys were illuminated through diffusion filters from a CRT placed immediately behind the array. Rewards consisted of the most preferred food items for each species: pieces of pine nut for pinyon jays and nutcrackers and halves of meal worm for scrub jays. These were delivered into a food cup centered at floor level at the rear of the chamber.

\section{Training}

The birds were habituated to the operant chamber and shaped to peck the side keys when they were illuminated in white. A central white "start" key was then added for six daily 36-trial sessions as an automatic precursor to presentation of an illuminated side key, and the response requirement for the side keys was increased to three pecks. Responses to the start key were subsequently made obligatory, and the birds were transferred to baseline training. During baseline training, the stimulus preferences of each bird were assessed over three daily 36-trial sessions in which they were shown the experimental stimuli but were not required to make differential responses. In baseline training for color reversal (Experiment 1), each bird was tested with trials in which, following a peck to the start key, one side key was illuminated in either red or green. For spatial reversal (Experiments 2 and 3), one of the two side keys was illuminated in white. In each case, the stimulus alternatives were presented equally often in each session, balanced across left and right side keys, and randomly ordered. The birds were rewarded when they pecked the illuminated key three times in succession. For each bird, the stimulus alternative with the longest first-peck latency in the baseline trials was considered nonpreferred and was used as the rewarded alternative in initial reversal training.

\section{Discrimination Trials}

At the start of each trial, the central start key was illuminated in white. If the key was not pecked within $15 \mathrm{~s}$, it was turned off, and the trial was reinitiated after a 3-s delay. When the start key was pecked, it was turned off, and both side keys were illuminated. In Experiment 1, the side keys presented a choice between red and green; each color occurred equally often on the left and right keys, randomly ordered within days, but responses to only one of the two were rewarded. In Exper- iments 2 and 3, the side keys were both illuminated in white, but, again, responses to only one of the two alternatives were rewarded. Upon three successive pecks to one of the side keys, the entire panel was darkened. If the correct key had been chosen, a reward was delivered to the food cup. After $10 \mathrm{~s}$, the food light was turned off, and another trial began $20 \mathrm{~s}$ later. If the wrong key was chosen, the next trial was presented after a 30-s delay. If the bird failed to peck either key three times within $60 \mathrm{~s}$, the panel was darkened, and the trial was repeated after a 30 -s delay.

All discrimination and reversal training in each of the three experiments was provided in daily 36-trial sessions. Subjects were given an initial session on each discrimination (color or position). Training sessions were then continued until the birds attained a criterion of $90 \%$ correct responses to the rewarded stimulus over three successive days. Once the criterion had been met for a given bird, reward contingencies were reversed for the following day's session. Each bird was given 20 such successive reversal treatments.

\section{Experiment 1: Color Reversal}

\section{Method}

The first experiment examined the effects of serial reversals on responses to two colored stimuli. The number of errors in the first session following each reversal was analyzed separately from the cumulative number of errors in all subsequent sessions prior to achieving the criterion. This provided a rough indication of the time course of the acquisition of the response. The error rate in reversal experiments characteristically declines over successive reversals, gradually converging on an asymptotic level (Mackintosh, 1974). To improve the fit of the observations to the assumptions of a general linear model, the number of errors by each bird in the initial and subsequent sessions of each round of training were transformed with natural logarithms prior to analysis. Results were analyzed with repeated measures analysis of variance (ANOVA). Significant main effects of species were explored with single-degree-offreedom comparisons of all species pairs to locate the source of the effect (Keppel, 1982).

Results

ANOVA on log-transformed errors during prereversal discrimination training revealed no significant first-session differences between species ( $M s=0.96$ for nutcrackers, 1.03 for pinyon jays, and 1.00 for scrub jays), $F(2,12)=0.26, p>.7$. There were, thus, no species differences in initial acquisition of the color task. Log error rates from Reversals 1 to 20 were blocked into five groups of four for ANOVA. There was a significant main effect of species on errors in the 1st session after reversals, $F(2,12)=8.50, p=.008$ (see Figure 1a). Planned comparisons between species pairs indicated that pinyon jays were significantly more accurate than either nutcrackers or scrub jays during their first postreversal sessions, $F(1,12) \geq 10.4, p \leq$ .007. There was a similar significant main effect of species on the errors in subsequent sessions, $F(2,12)=4.60, p=.03$ (see Figure $1 b$ ), which was primarily due to the difference between pinyon jays and scrub jays, $F(1,12)=9.20, p=.01$. Error rates declined significantly for all species across successive reversal blocks: 1st sessions, $F(4,48)=76.70, p<.001$; later sessions, 


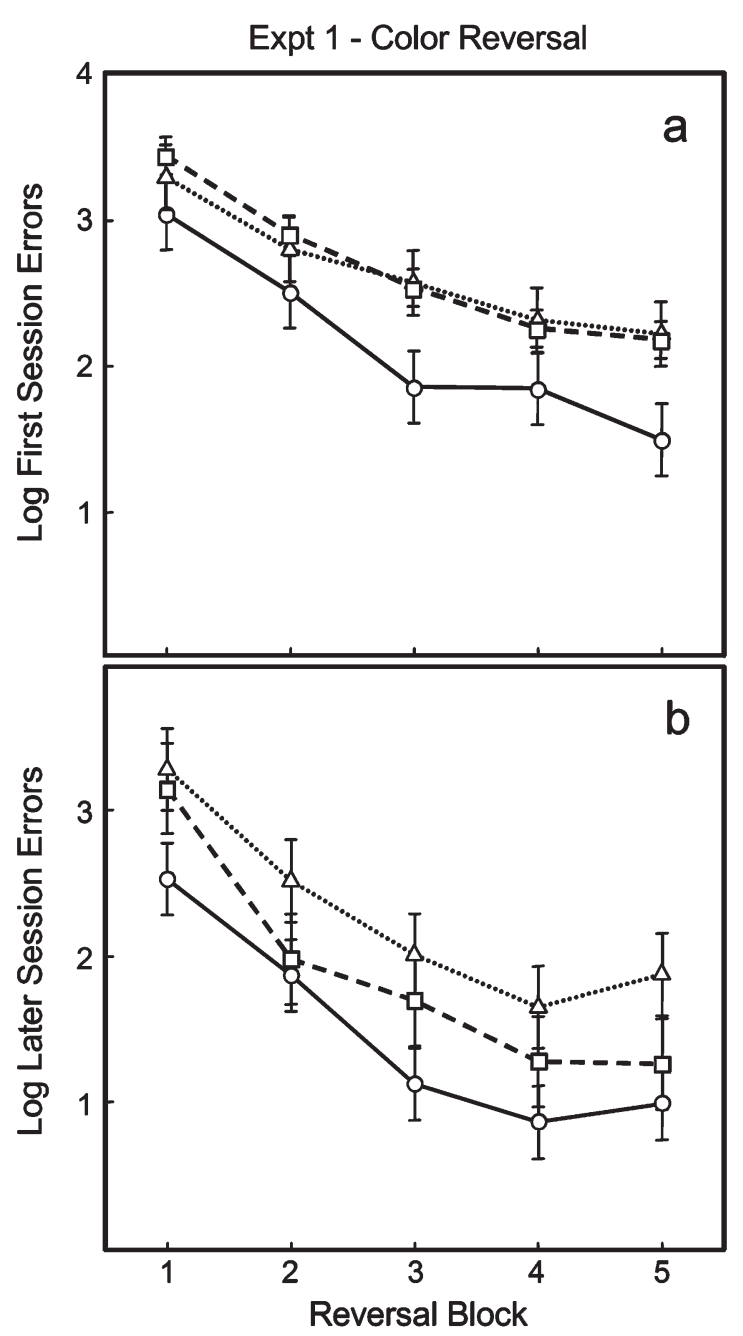

Figure 1. Error rates over five blocks of four successive reversals of a two-choice color discrimination task. Circles and solid lines signify data from 5 pinyon jays; triangles and dotted lines, data from 5 scrub jays; squares and dashed lines, data from 5 nutcrackers. Data points in (a) are mean log errors in the first postreversal session across birds within species; in (b), they are mean log errors in all subsequent sessions to criterial performance across birds within species. Error bars bracket the pooled within-subjects standard error estimate for each species. Expt $=$ Experiment.

$F(4,48)=75.8, p<.001$. The number of sessions required to first achieve the criterial level of $90 \%$ correct showed a corresponding drop across reversals. The mean first criterial session declined from 5.4 on the 1st reversal to 2.0 on the 20th for nutcrackers, from 4.6 to 1.4 for pinyon jays, and from 6.8 to 2.4 for scrub jays. There were, however, no significant Species $\times$ Block interactions, $F(8,48) \leq 1.31, p>.2$, indicating that the rate of improvement over successive reversals was consistent across species.

\section{Discussion}

Although the three species did not differ in their initial acquisition of the discrimination task, pinyon jays responded more rapidly than scrub jays and nutcrackers to reversals in reward contingency for colored stimuli. All three species improved in performance over the 20 serial reversals, but the initially greater accuracy of pinyon jays in this task was maintained over the full course of the experiment. Species differences were less evident in the later sessions of each reversal, apparently because individual subjects varied widely in the rate at which they acquired new reinforcement contingencies. Some birds of each species quickly learned to shift responses on the basis of just a few unrewarded trials; others invariably took much longer. As a result, the 1st session of each reversal was generally the most sensitive to species differences in error rates. To determine whether the superiority of pinyon jays at serial reversal was limited to color stimuli, we contrasted these initial results with those from a reversal task based on positional cues.

\section{Experiment 2: Spatial Reversal}

\section{Method}

This experiment followed Experiment 1 after a 7-day hiatus, using the same set of subjects. Two of the scrub jays died, however, prior to the fourth reversal, though no evidence of injury or infection was found at postmortem. As a result, neither of these birds was included in the analysis. During acquisition and reversal trials, both side keys were illuminated in white, but responses to only one of them were rewarded. Providing rewards in a food cup at the rear of the operant box ensured that the birds could not solve the spatial discrimination task by simply perching in front of the correct key. Analytical and training methods were comparable to those used in Experiment 1.

\section{Results}

ANOVA on log-transformed errors during prereversal discrimination training revealed a significant species difference $(M=0.34$ for nutcrackers, 1.69 for pinyon jays, 2.03 for scrub jays), $F(2,10)=16.80, p<.001$. It was attributable to significantly faster learning of the initial discrimination by nutcrackers than by either of the other two species, $F(1,10) \geq 21.6, p<$ .001 . This superiority of nutcrackers at spatial discrimination learning was only evident in the first prereversal training session. Errors from subsequent training sessions prior to achieving criterion showed no significant main effect of species, $F(2$, 10) $=1.46, p>.2$.

Reversal treatments were blocked into five groups of four for analysis, and the mean log-transformed errors in initial and subsequent sessions for each block for each bird were subjected to repeated measures ANOVA. Error rates declined significantly for all species across successive reversal blocks, but the effect was only evident in the first postreversal sessions, $\mathrm{F}(4,40)=24.30, \mathrm{p}<.001$ (see Figure $2 \mathrm{a}$ ). Subsequent session errors showed no main effect of block, $F(4,40)=1.97$, p $>.1$ (see Figure $2 b$ ), suggesting that all three species rapidly reached an asymptotic level of performance. This is supported by the minimal changes observed in the number of sessions required to first achieve criterial level performance. The mean first criterial session declined from 2.2 on the 1st reversal to 1.2 on the 20th for nutcrackers, from 2.0 to 1.2 for pinyon jays, and from 2.7 to 1.7 for scrub jays. There was no significant main effect of species on error rates in either the initial sessions, $F(2,10)=$ $1.04, \mathrm{p}>.3$, or the subsequent ones, $\mathrm{F}(2,10) \leq 1.01, \mathrm{p}>.3$. The 


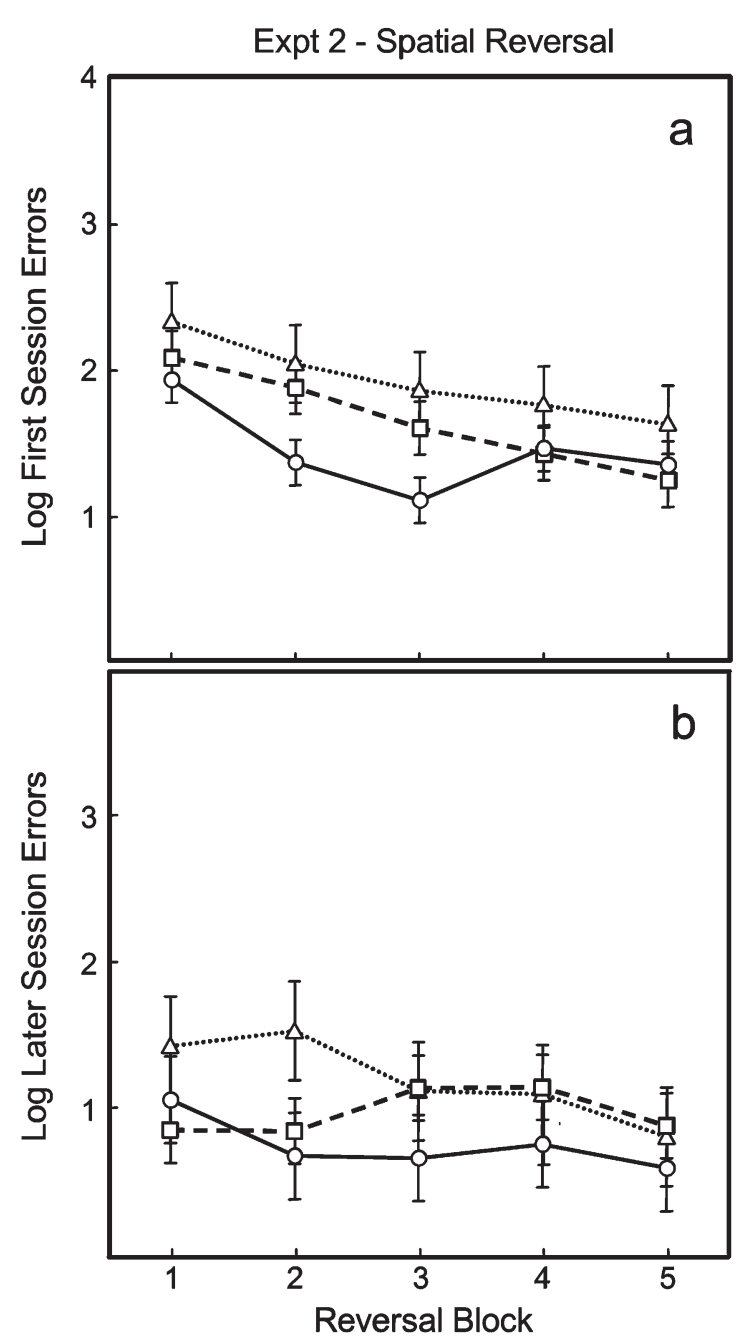

Figure 2. Error rates over five blocks of four successive reversals of a two-choice spatial discrimination task. Circles and solid lines signify data from 5 pinyon jays; triangles and dotted lines, data from 3 scrub jays; squares and dashed lines, data from 5 nutcrackers. Data points in (a) are mean log errors in the first postreversal session across birds within species; in (b), they are mean log errors in all subsequent sessions to criterial performance across birds within species. Error bars bracket the pooled within-subjects standard error estimate for each species. Expt $=$ Experiment.

Species $\times$ Block interaction was statistically significant for initial session errors, $\mathrm{F}(8,40)=2.81, \mathrm{p}=.014$, however, apparently reflecting the greater accuracy of pinyon jays over the first 12 reversals (see Figure 2a).

\section{Discussion}

Clark's nutcrackers acquired an initial spatial discrimination more rapidly than pinyon jays or scrub jays, but pinyon jays again showed a higher level of reversal performance, in that they appeared to converge more rapidly to an asymptotic error level. Experiment 2 was clearly less demanding than Experiment 1 for all three species, however. As a result, the range of error rates was limited by floor effects, which may have interfered with our ability to detect species differences. The greater accuracy exhibited by all three species on this spa- tial task, in contrast to the color task, suggests either that spatial reversal is inherently a less difficult problem or that there were significant carryover effects of the birds' prior training on color stimuli. Spatial position has been found to be less difficult to reverse than color or shape in some taxa (reviewed in Day, Ismail, \& Wilczynski, 2003) but more difficult in others (e.g., Doty \& Combs, 1969). Transfer between two series of reversals when the discriminated dimensions are changed (i.e., between color and position or between color and orientation) has been found to be negative or negligible in studies on both pigeons and rats (Durlach \& Mackintosh, 1986; Mackintosh \& Holgate, 1969; Mackintosh, McGonigle, Holgate, \& Vanderver, 1968). To determine whether the improved spatial performance of corvids could be attributable to prior training on colored stimuli, we conducted another series of spatial reversals, this time using naive subjects.

\section{Experiment 3: Spatial Reversal Using Naive Subjects}

\section{Method}

New groups of 5 pinyon jays and 5 scrub jays, all naive to operant procedures, were trained and tested as described in the General Method section. No naive captive nutcrackers were available at the time this experiment was performed. Analytical and training methods were otherwise identical to those used in Experiment 2.

Results

ANOVA on log-transformed errors during prereversal discrimination training revealed no significant differences between pinyon and scrub jays $(M=2.36$ for pinyon jays, 2.05 for scrub jays), $F(1,8)=0.86, p>3$. As in previous experiments, reversal treatments were blocked into five groups of four for analysis, and the mean log-transformed errors in 1st sessions and subsequent sessions for each reversal block for each bird were subjected to repeated measures ANOVA. Unlike Experiment 2 , there was a significant main effect of species on 1st session errors, $F(1,8)=8.90, p<.018$ (see Figure 3a), though not on subsequent session errors, $F(1,8)=0.74, p>.4$ (see Figure $3 b)$. Pinyon jays consistently compensated more rapidly than scrub jays to reversed spatial discrimination. Both 1st session and subsequent session errors declined significantly across successive blocks: 1st sessions, $F(4,31)=63.00, p<.001$; later sessions, $F(4,31)=9.14, p<.001$. As might be expected, the number of sessions to first criterial performance also declined across reversals, though the magnitudes were comparable to those observed in Experiment 2. The mean first criterial session for pinyon jays declined from 2.6 to 1.3, and that for scrub jays declined from 2.8 to 1.8. As in Experiment 1, there were no significant Species $\times$ Block interactions, $F(4,31) \leq 1.98, p \geq$ .12 , indicating that the rate of improvement over successive reversals was consistent across species.

The naive subjects in this experiment appeared to have found the spatial reversal task more difficult than did the experienced subjects in Experiment 2. We conducted a mixedmodel ANOVA on the results of Experiments 2 and 3, which revealed no significant main effect of prior experience, $F(1$, $15)=2.97, p>$.1. The interaction of experience with reversal block was, however, statistically significant for initial session errors, $F(4,55)=8.97, p<.001$, apparently reflecting the earlier 


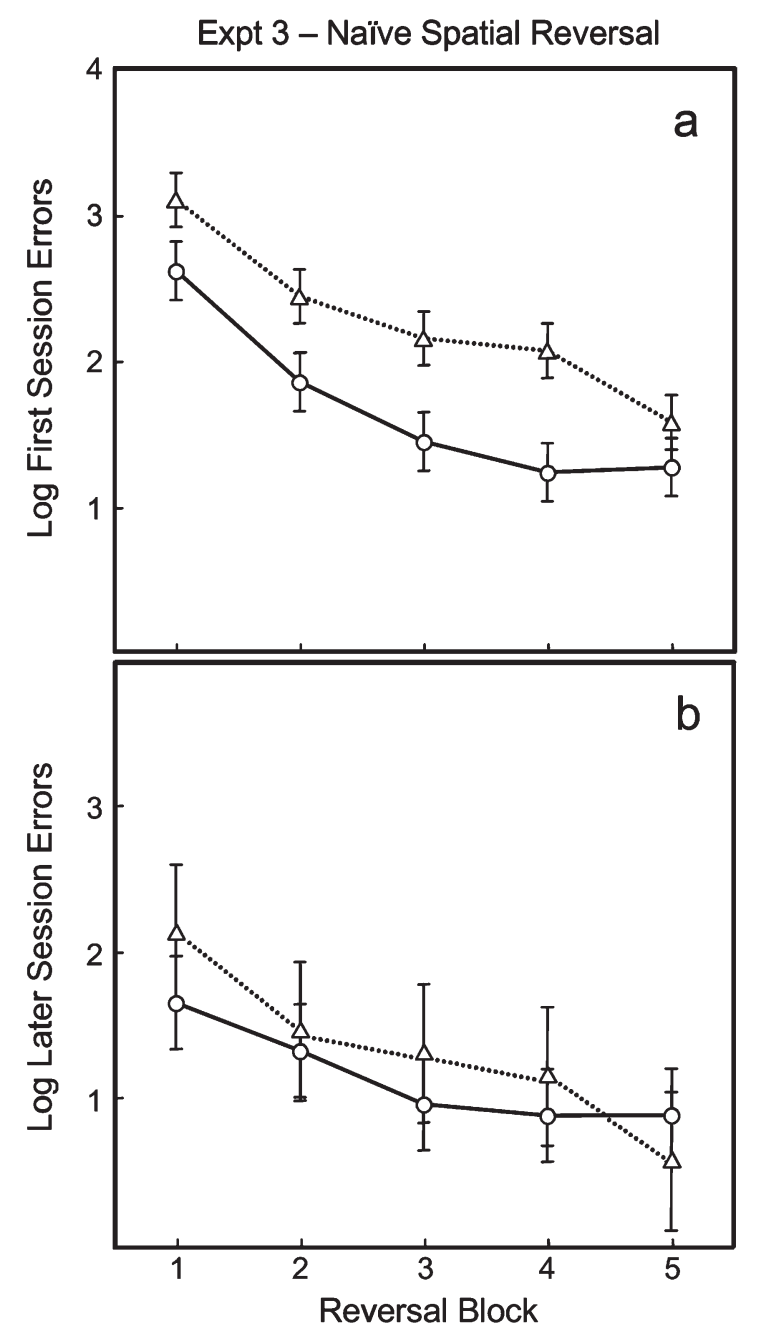

Figure 3. Error rates over five blocks of four successive reversals of a two-choice discrimination of spatial position, using naive subjects. Circles and solid lines signify data from 5 pinyon jays, and triangles and dotted lines, data from 5 scrub jays. Data points in (a) are mean $\log$ errors in the first postreversal session across birds within species; in (b), they are mean log errors in all subsequent sessions to criterial performance across birds within species. Error bars bracket the pooled within-subjects standard error estimate for each species. Expt = Experiment.

attainment of asymptotic error levels by the experienced birds. There was also evidence that naive jays found the spatial reversal task easier to learn than the color reversal. A mixedmodel ANOVA comparing the results of Experiments 1 and 3 revealed a significant main effect of stimulus type (color vs. spatial) on initial session errors, $F(1,16)=11.70, p=.004$. Spatial reversal thus appears to be both inherently less difficult than color reversal for these species and susceptible to significant carryover effects from prior reversal training.

\section{Discussion}

Pinyon jays were more accurate than scrub jays in initial reversal performance on spatial discriminations throughout all 20 reversals (see Figure 3a). The absence of a significant Species $\times$ Block interaction, which was also found in the color reversals, suggests again that the high accuracy of pinyon jays was maintained at consistent levels throughout the experiment and confirms that the significant species interaction in Experiment 2 was probably due to rapid convergence on asymptotic error levels. As in Experiment 1, the species effect was less evident in subsequent sessions, because of large differences between subjects in the rate at which they converged on criterial levels of performance. Although the results confirm that spatial reversals were less difficult for jays than were color reversals, they also indicate that prior experience with the color reversal task improved performance on the subsequent spatial reversal task, a positive transfer between the color and spatial reversal series.

\section{General Discussion}

In all three experiments, pinyon jays displayed significantly lower error rates than Clark's nutcrackers or scrub jays following serial reversals of reward contingencies. The size of the species difference was similar for naive birds with both spatial and color stimuli, and it was most apparent in the first session following each reversal. The superior performance of pinyon jays was, thus, manifested even when the birds first encountered reversed contingencies, when differences in flexibility in the face of value change might be expected to be most consequential. As with most other species that have been tested in serial reversals (Davey, 1989; Mackintosh, 1974), all three corvid species progressively reduced their first-session errors, eventually learning to switch quickly to the alternative stimulus on the basis of a few unrewarded trials. There were no species differences in the rate of improvement across successive reversals, but this may have been a result of the relative simplicity of the discrimination task. Hile (1998) also compared reversal performance in a range of corvid species, but she used a more complex design that involved serial reversals of two equivalence sets of four colored blocks. Pinyon jays showed a significant decline in the number of errors across successive reversals in Hile's study, but the task was sufficiently difficult that neither scrub jays nor Mexican jays demonstrated any sign of progressive improvement in performance.

The species contrasts were not attributable to differences in rates of discrimination learning. Nutcrackers acquired an initial spatial discrimination more rapidly than pinyon or scrub jays, which is consistent with their documented superiority at many tasks involving spatial memory (Balda et al., 1996; Bednekoff et al., 1997; Kamil et al., 1994), but there were no significant species differences in acquisition of the initial color discrimination. A similar differential effect of stimulus modality was shown in an earlier comparative study that used delayed nonmatching to sample (Olson et al., 1995). Nutcrackers outperformed pinyon jays and scrub jays in this procedure when spatial cues were used, but when the task used nonspatial cues, there were no significant species differences. Selection for accurate cache retrieval appears to have enhanced the memorial components of spatial processing in nutcrackers, but without affecting other aspects of spatial cognition, such as spatial perception (Gibson \& Kamil, 2005) or, in the current study, flexibility in the face of changed values of spatial locations.

It has been argued that serial reversal may engage a broader, more generalized learning process, referred to as learning the principle of reversal (Shettleworth, 1998) or developing a win-stay, lose-shift strategy (Bessemer \& Stollnitz, 1971; Davey, 1989; Macphail, 1982). The best evidence of 
such generalized learning seems to be the occurrence of positive transfer between successive serial reversal or learning set tasks that use disparate stimulus dimensions (Macphail, 1982). On this basis, chimpanzees and several species of macaques appear to develop generalized strategies (reviewed in Macphail, 1982), whereas rats, cats, and pigeons do not (Durlach \& Mackintosh, 1986; Mackintosh \& Holgate, 1969; Mackintosh et al., 1968; Warren, 1966). It is striking that all three of the corvid species in the current study showed significant positive transfer between serial reversals of color cues and those of positional stimuli. Blue jays (Cyanocitta cristata) have shown positive transfer between serial reversal and learning set tasks (Kamil, Jones, Pietrewicz, \& Mauldin, 1977), suggesting that the capability for developing generalized learning strategies may be broadly distributed among corvids.

The primary environmental factor that differentiates pinyon jays from both scrub jays and nutcrackers is the complexity of their social system. The results, therefore, suggest that behavioral flexibility, as measured by the rate of recovery from a reversed reward association, may be more strongly associated with social complexity than with ecological or spatial complexity in corvids. Animals in complex societies, we might suggest, must deal with continual fluctuations in social context, as individuals move about within the social group or undergo changes in status or motivational level. As a result, highly social species should be relatively flexible, showing a predisposition to switch fluidly among response alternatives (Easton, 2005). Whether this constitutes evidence of a cognitive "module," a specific mechanism responsible for behavioral flexibility in the face of changed stimulus values, is open to argument (Emery, 2006; Lefebvre \& Bolhuis, 2003; Shettleworth, 1998, 2000). It seems unlikely that reversal performance is functionally or anatomically equivalent to other types of behavioral flexibility. Studies by Lefebvre and his associates, however, have found a significant correlation between reversal learning performance and rates of foraging innovation across species (Lefebvre \& Bolhuis, 2003; Lefebvre, Reader, \& Sol, 2004; Timmermans, Lefebvre, Boire, \& Basu, 2000). This suggests either that these two manifestations of behavioral flexibility are subject to similar selective pressures or, more likely, that they are both correlated with a third, more global variable, such as relative brain size.

There is converging evidence from a variety of neurobiological studies in both mammals and birds suggesting that performance in reversal learning tasks may be determined by a circumscribed set of cortical neurons (Kringelbach \& Rolls, 2003; reviewed in Watanabe, 2006). The nidopallium is commonly considered the avian analogue to the mammalian prefrontal cortex (Hartmann \& Güntürkün, 1998). Lesions or chemically induced disruption of this brain area destroy the bird's ability to reverse a learned association but do not interfere with initial acquisition of a visual discrimination (Hartmann \& Güntürkün, 1998; Lissek, Diekamp, \& Güntürkün, 2002). There are also indications that the wulst plays a role in reversal learning. Wulst lesions do not enhance perseveration, but they do appear to interfere with acquisition of new behaviors (Watanabe, 2006). Crucial aspects of the mechanism underlying reversal learning thus appear to be highly localized, both anatomically and functionally, consistent with a modular view of this cognitive ability (Lefebvre \& Bolhuis, 2003). Neuroanatomical comparisons of size and neuronal density of the wulst and nidopallium in North American corvids could pro- vide a further basis for investigation of modularity in reversal learning, analogous to the studies performed on hippocampal volume and structure in food-caching birds (Garamszegi \& Eens, 2004; Sherry, 2006).

\section{References}

Balda, R. P. (2002). Pinyon jay (Gymnorhinus cyanocephalus). In A. Poole $\&$ F. Gill (Eds.)The birds of North America (Vol. 605). Philadelphia: Birds of North America.

Balda, R. P., \& Kamil, A. C. (1998). The ecology and evolution of spatial memory in corvids of the Southwestern USA: The perplexing pinyon jay. In. R. P. Balda, I. M. Pepperberg, \& A. C. Kamil (Eds.), Animal cognition in nature (pp. 29-64). New York: Academic Press.

Balda, R. P., Kamil, A. C., \& Bednekoff, P. A. (1996). Predicting cognitive capacities from natural histories: Examples from four corvid species. Current Ornithology, 13, 33-66.

Bednekoff, P. A., \& Balda, R. P. (1997). Clark's nutcracker spatial memory: Many errors might not be due to forgetting. Animal Behaviour, 54, 691-698.

Bednekoff, P. A., Balda, R. P., Kamil, A. C., \& Hile, A. L. (1997). Longterm spatial memory in four seed caching corvid species. Animal Behaviour, 53, 335-341.

Bessemer, D. W., \& Stollnitz, F. (1971). Retention of discriminations and an analysis of learning set. In A. M. Schrier \& F. Stollnitz (Eds.), Behavior of nonhuman primates (Vol. 4, pp. 1-58). New York: Academic Press.

Bitterman, M. E. (1965). Phyletic differences in learning. American Psychologist, 20, 396-410.

Blumenstein, D. T., \& Armitage, K. B. (1998). Life history consequences of social complexity: A comparative study of ground-dwelling sciurids. Behavioral Ecology, 9, 8-19.

Bond, A. B., Kamil, A. C., \& Balda, R. B. (2003). Social complexity and transitive inference in corvids. Animal Behaviour, 65, 479-487.

Breland, K., \& Breland, M. (1961). The misbehavior of organisms. American Psychologist, 16, 681-684.

Burghardt, G. M. (2005). The genesis of animal play: Testing the limits. Cambridge, MA: MIT Press.

Carmen, W. J. (2004). Noncooperative breeding in the California scrubjay. Studies in Avian Biology, 28, 1-100.

Curry, R. L., Peterson, A. T., \& Lange, T. A. (2002). Western scrubjay (Aphelocoma californica). In A. Poole \& F. Gill (Eds.)The birds of North America (Vol. 712). Philadelphia: Birds of NA.

Davey, G. (1989). Ecological learning theory. London: Routledge.

Day, L. B., Crews, D., \& Wilczynski, W. (1999). Spatial and reversal learning in congeneric lizards with different foraging strategies. Animal Behaviour, 57, 393-407.

Day, L. B., Ismail, N., \& Wilczynski, W. (2003). Use of position and feature cues in discrimination learning by the whiptail lizard (Cnemidophorus inornatus). Journal of Comparative Psychology, 117, 440-448.

de Waal, F. B. M., \& Tyack, P. L. (Eds.). (2003). Animal social complexity. Cambridge, MA: Harvard University Press.

Diamond, J., \& Bond, A. B. (1999). Kea, bird of paradox: The evolution and behavior of a New Zealand parrot. Berkeley: University of California Press.

Doty, B. A., \& Combs, W. C. (1969). Reversal learning of object and positional discriminations by mink, ferrets and skunks. Quarterly Journal of Experimental Psychology, 21, 58-62.

Durlach, P. J., \& Mackintosh, N. J. (1986). Transfer of serial reversal learning in the pigeon. Quarterly Journal of Experimental Psychology, $38 B, 81-95$.

Easton, A. (2005). Behavioural flexibility, social learning, and the frontal cortex. In A. Easton \& N. J. Emery (Eds.), The cognitive neuroscience of social behaviour (pp. 59-80). New York: Psychology Press. 
Emery, N. J. (2006). Cognitive ornithology: The evolution of avian intelligence. Philosophical Transactions of the Royal Society, Series B, 361, 23-43.

Espinosa de los Monteros, A., \& Cracraft, J. (1997). Intergeneric relationships of the New World jays inferred from cytochrome $b$ gene sequences. Condor, 99, 490-502.

Felsenstein, J. (1985). Phylogenies and the comparative method. American Naturalist, 125, 1-15.

Garamszegi, L. Z., \& Eens, M. (2004). The evolution of hippocampus volume and brain size in relation to food-hoarding in birds. Ecology Letters, 7, 1216-1224.

Gibson, B. M., \& Kamil, A. C. (2005). The fine-grained spatial abilities of three seed-caching corvids. Learning and Behavior, 33, 59-66.

Godfrey-Smith, P. (2002). Environmental complexity and the evolution of cognition. In R. Sternberg \& J. Kaufman (Eds.), The evolution of intelligence (pp. 233-249). Mahwah, NJ: Erlbaum.

Hartmann, B., \& Güntürkün, O. (1998). Selective deficits in reversal learning after neostriatum caudolaterale lesions in pigeons: Possible behavioral equivalencies to the mammalian prefrontal system. Behavioural Brain Research, 96, 125-133.

Harvey, P. H., \& Pagel, M. D. (1991). The comparative method in evolutionary biology. New York: Oxford University Press.

Hile, A. G. (1998). Comparative tests of general intelligence between social and asocial North American seed-caching corvids (Doctoral dissertation, Northern Arizona University, 1998). Dissertation Abstracts International, 59, 3287.

Holt, J., Holt, L. E., \& Pelham, T. W. (1996). Flexibility redefined. In T. Bauer (Ed.), Biomechanics in sports (Vol. 13, pp. 170-174). Thunder Bay, Ontario, Canada: Lakehead University Press.

IEEE. (1990). IEEE standard computer dictionary. New York: Author.

Jones, C. B. (2005). Behavioral flexibility in primates: Causes and consequences. New York: Springer-Verlag.

Kamil, A. C. (1988). A synthetic approach to the study of animal intelligence. In D. Leger (Ed.), Nebraska Symposium on Motivation: Vol. 35. Comparative perspectives in modern psychology (pp. 230-257). Lincoln: University of Nebraska Press.

Kamil, A. C., Balda, R. P., \& Olson, D. J. (1994). Performance of four seed-caching species in the radial-arm maze analog. Journal of Comparative Psychology, 108, 385-393.

Kamil, A. C., Jones, T. B., Pietrewicz, A., \& Mauldin, J. E. (1977). Positive transfer from successive reversal training to learning set in blue jays (Cyanocitta cristata). Journal of Comparative and Physiological Psychology, 91, 79-86.

Keppel, G. (1982). Design and analysis: A researcher's handbook (2nd ed.). Englewood Cliffs, NJ: Prentice Hall.

Kringelbach, M. L., \& Rolls, E. T. (2003). Neural correlates of rapid reversal learning in a simple model of human social interaction. NeuroImage, 20, 1371-1383.

Lefebvre, L., \& Bolhuis, J. J. (2003). Positive and negative correlates of feeding innovations in birds: Evidence for limited modularity. In S. M. Reader \& K. N. Laland (Eds.), Animal innovation (pp. 39-61). Oxford, England: Oxford University Press.

Lefebvre, L., Reader, S. M., \& Sol, D. (2004). Brains, innovations and evolution in birds and primates. Brain Behavior and Evolution, 63, 233-246.

Lewis, J. L., \& Kamil, A. C. (2006). Interference effects in the memory for serially presented locations in Clark's nutcrackers, Nucifraga columbiana. Journal of Experimental Psychology: Animal Behavior Processes, 32, 407-418.

Lissek, S., Diekamp, B., \& Güntürkün, O. (2002). Impaired learning of a color reversal task after NMDA receptor blockade in the pigeon (Columba livia) associative forebrain (neostriatum caudolaterale). Behavioral Neuroscience, 116, 523-529.

Lorenz, K. Z. (1981). The foundations of ethology. New York: Springer-Verlag.

Mackintosh, N. J. (1974). The psychology of animal learning. New York: Academic Press.
Mackintosh, N. J., \& Holgate, V. (1969). Serial reversal training and nonreversal shift learning. Journal of Comparative and Physiological Psychology, 67, 89-93.

Mackintosh, N. J., McGonigle, B., Holgate, V., \& Vanderver, V. (1968). Factors underlying improvement in serial reversal learning. Canadian Journal of Psychology, 22, 85-95.

Macphail, E. M. (1982). Brain and intelligence in vertebrates. Oxford, England: Clarendon Press.

Marzluff, J. M., \& Balda, R. P. (1992). The pinyon jay: Behavioral ecology of a colonial and cooperative corvid. London: T \& A. D. Poyser.

Monroe, B. L., \& Sibley, C. G. (1993). A world checklist of birds. New Haven, CT: Yale University Press.

Olson, D. J., Kamil, A. C., Balda, R. P., \& Nims, P. J. (1995). Performance of four seed-caching corvid species in operant tests of nonspatial and spatial memory. Journal of Comparative Psychology, 109, 173-181.

Paz-y-Miño, C. G., Bond, A. B., Kamil, A. C., \& Balda, R. P. (2004, August 12). Pinyon jays use transitive inference to predict social dominance. Nature, 430, 778-781.

Reader, S. M., \& Laland, K. N. (2003). Animal innovation: An introduction. In S. M. Reader \& K. N. Laland (Eds.), Animal innovation (pp. 3-35). Oxford, England: Oxford University Press.

Robinson, M. H. (1990). Predator-prey interactions, informational complexity, and the origins of intelligence. In D. L. Evans \& J. O. Schmidt (Eds.), Insect defenses: Adaptive mechanisms and strategies of prey and predators (pp. 129-149). Albany: State University of New York Press.

Sherry, D. F. (2006). Neuroecology. Annual Review of Psychology, 57, 167-197.

Shettleworth, S. J. (1998). Cognition, evolution, and behavior. Oxford, England: Oxford University Press.

Shettleworth, S. J. (2000). Modularity and the evolution of cognition. In C. Heyes \& L. Huber (Eds.), The evolution of cognition (pp. 4360). Cambridge, MA: MIT Press.

Shultz, S., \& Dunbar, R. I. M. (2006). Both social and ecological factors predict ungulate brain size. Proceedings of the Royal Society of London, Series B, 273, 207-215.

Sol, D., Timmermans, S., \& Lefebvre, L. (2002). Behavioural flexibility and invasion success in birds. Animal Behaviour, 63, 495-502.

Timmermans, S., Lefebvre, L., Boire, D., \& Basu, P. (2000). Relative size of the hyperstriatum ventrale is the best predictor of feeding innovation rate in birds. Brain Behavior and Evolution, 56, 196-203.

Tomasello, M., \& Call, J. (1997). Primate cognition. Oxford, England: Oxford University Press.

Tomback, D. F. (1998). Clark's nutcracker (Nucifraga columbiana). In A. Poole \& F. Gill (Eds.), The birds of North America (Vol. 331). Philadelphia: Birds of NA.

Upton, D. M. (1994). The management of manufacturing flexibility. California Management Review, 36, 72-89.

Vander Wall, S. B., \& Balda, R. P. (1981). Ecology and evolution of food-storage behavior in conifer-seed caching corvids. Zeitschrift für Tierpsychologie, 56, 217-242.

Warren, J. M. (1965) The comparative psychology of learning. Annual Review of Psychology, 16, 95-118.

Warren, J. M. (1966). Reversal learning and the formation of learning sets by cats and rhesus monkeys. Journal of Comparative and Physiological Psychology, 61, 421-428.

Watanabe, S. (2006). The neural basis for cognitive flexibility in birds. In E. A. Wasserman \& T. R. Zentall (Eds.), Comparative cognition: Experimental explorations of animal intelligence (pp. 619-639). Oxford, England: Oxford University Press.

Submitted February 14, 2007; revised May 21, 2007; accepted May 24, 2007. 